\title{
Design, Rationale, Methodology, and Aims of a Greek Prospective Idiopathic Pulmonary Fibrosis Registry: Investigating Idiopathic Pulmonary Fibrosis in Greece (INDULGE IPF)
}

\author{
Demosthenes Bouros $^{\mathrm{a}}$ Zoe Daniil $^{\mathrm{b}}$ Despoina Papakosta ${ }^{\mathrm{c}}$ \\ Katerina M. Antoniou ${ }^{d}$ Katerina Markopoulou ${ }^{e}$ \\ Likurgos Kolilekas $^{f}$ George Konstantopoulos ${ }^{g}$ \\ Spyros Papiris $^{\text {h }}$ on behalf of the INDULGE IPF Study Group
}

\begin{abstract}
a 1st Academic Department of Pneumonology, Hospital for Diseases of the Chest "Sotiria," Medical School, National and Kapodistrian University of Athens, Athens, Greece; ${ }^{\text {b }}$ Respiratory Medicine Department, University of Thessaly School of Medicine, University Hospital of Larissa, Larissa, Greece; 'Pulmonary Medicine Department, General Hospital of Thessaloniki "G. Papanikolaou," Aristotle University of Thessaloniki Medical School, Thessaloniki, Greece; ${ }^{d}$ Thoracic Medicine Department, University Hospital of Heraklion, Heraklion, Greece; ${ }^{\mathrm{e} N H S}$ Pulmonology

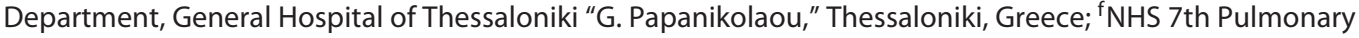
Department and Asthma Center, Hospital for Diseases of the Chest "Sotiria," Athens, Greece; ${ }^{9}$ BI Hellas, Medical Department, Athens, Greece; ${ }^{\mathrm{h}}$ 2nd Respiratory Medicine Department, Medical School, National and Kapodistrian University of Athens, Attikon General Hospital, Athens, Greece
\end{abstract}

\section{Keywords}

Greece - Idiopathic pulmonary fibrosis registry ·

INDULGE IPF · IPF

\begin{abstract}
Background: Idiopathic pulmonary fibrosis (IPF) is a chronic, fibrosing interstitial pneumonia of unknown origin. Despite the fact that the guidelines on the diagnosis and management of the disease were updated in 2015, incorporating novel agents recently introduced in the therapeutic approach of IPF, there is a lack of data on the epidemiology, disease status, and treatment in clinical practice. Contemporary data provided by national registries in IPF provide valu-
\end{abstract}

able information to guide clinical management of the disease in the real-world setting, adjusted to the local needs. Objective: Investigating Idiopathic Pulmonary Fibrosis in Greece (INDULGE IPF) is a Greek observational registry aiming at gaining further knowledge on the characteristics, management, progression, and outcomes of patients with IPF treated under real-world, clinical practice conditions in Greece. Methods: Approximately 300 patients will be enrolled consecutively in seven reference centers, constituting the largest IPF registry ever established in Greece. Conclusion: This registry is expected to provide data on the characteristics of IPF patients in Greece and the entire clinical management during the course of the disease.

(c) 2018 S. Karger AG, Base

\section{KARGER}

E-Mail karger@karger.com

www.karger.com/res
(C) 2018 S. Karger AG, Basel

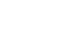




\section{Introduction}

Idiopathic pulmonary fibrosis (IPF) is defined as a specific form of chronic, progressive interstitial pneumonia of unknown cause, limited to the lungs, occurring primarily in older adults, with preponderance in men and previous or current smokers [1,2]. IPF is associated with chronic dyspnea and cough as well as progressive loss of lung function [2].

The diagnosis of the disease is currently based on the $2011 \mathrm{ATS} / \mathrm{ERS} / \mathrm{JRS} / \mathrm{ALAT}$ guidelines [1] and requires exclusion of identifiable causes of interstitial lung disease as well as identification of a pattern of usual interstitial pneumonia either on high-resolution computed tomography or on surgical lung biopsy. However, the clinical course of disease is variable with some patients progressing slowly, others rapidly, and some patients experiencing acute exacerbations that are associated with increased morbidity and mortality [3]. Currently, there are no prognostic biomarkers that could predict the clinical course of IPF for newly diagnosed individual patients. The decline in forced vital capacity (FVC) though is predictive of mortality. In general, IPF is the most severe among the idiopathic interstitial pneumonias and has a poor prognosis, with a median overall survival of 5 years [4].

\section{Novel Treatments in IPF}

Until recently there was no effective pharmacological treatment for IPF other than lung transplantation, which was considered the only survival-improving intervention. Since 2011, two novel agents, pirfenidone and nintedanib, have been approved by both the European Medicines Agency and the Food and Drug Administration for patients with IPF, on the basis of phase III randomized clinical trials (RCTs) showing that these agents reduce the decline in lung function in comparison to placebo [5-8]. Specifically, pirfenidone is a pyridone, a low-molecularweight molecule that exhibits anti-inflammatory and antifibrotic properties, although its exact mechanism of action remains unknown. In vivo, pirfenidone downregulates several cytokines that are implicated in IPF pathogenesis, such as platelet-derived growth factor, transforming growth factor beta, and tumor necrosis factor alpha $[9,10]$. A prespecified pooled analysis of the RCTs CAPACITY and ASCEND, testing the efficacy of pirfenidone versus placebo in patients with IPF, showed that pirfenidone significantly reduced the decline in FVC, the proportion of patients who had a decline of $>10 \%$ in predicted FVC or who died (16.5 vs. $31.8 \%, p=0.001)$, and significantly increased the proportion of patients with no decline in FVC compared with placebo (22.7 vs. 9.7\%, $p=0.001)$. Moreover, pirfenidone reduced all-cause and IPF-related mortality at 1 year by $48 \%(p=0.01)$ and $68 \%$ $(p=0.006)$, respectively compared with placebo [11].

Nintedanib is a multitarget tyrosine kinase inhibitor with activity against vascular endothelial growth factor, fibroblast growth factor, and platelet-derived growth factor receptors, which are implicated in the pathogenesis of IPF $[12,13]$. Three RCTs - one phase 2 study (TOMORROW) and two replicate phase 3 studies (INPULSIS-1 and INPULSIS-2) - have been conducted to evaluate the efficacy of nintedanib in IPF $[7,8]$. The two phase 3 trials met their primary endpoint showing that nintedanib at a dose of $150 \mathrm{mg}$ twice daily reduced in a statistically significant manner both the percentage of patients with $>10 \%$ absolute decline in FVC and the adjusted annual rate of decline in FVC [8]. Furthermore, pooled analysis of all three RCTs conducted with nintedanib in IPF showed a trend for reduced mortality and statistically significant reduction in the number of acute exacerbations among IPF patients treated with nintedanib [14].

Both drugs have also received conditional recommendation for use according to the latest ATS/ERS/JRS/ALAT clinical practice guidelines for IPF [15]. Despite the substantial efforts that have been made to investigate the efficacy and safety of new drugs in controlled clinical trials, there are still many questions regarding the medical management of IPF patients that remain unanswered, and there is a paucity of data on the implementation of clinical practice guidelines in everyday clinical practice [16]. This is attributed to three main limitations: (1) the lack of epidemiological data for a disease with a relative low incidence, (2) the heterogeneity of the disease as reflected in the diagnostic criteria, the differences in the clinical course of patients, and the lack of predictive or prognostic biomarkers, and (3) the cost of novel agents that may affect their clinical use [17].

Regarding the first limitation, the consensus statement issued by the ATS/ERS/JRS/ALAT [1] states that the epidemiological data on the incidence and prevalence of IPF are limited. IPF prevalence varies widely between 1.25 and 63 cases per 100,000 of population in several epidemiological studies [3,18-22]. The incidence of IPF is also variable. A systematic review reported an incidence range of 2.8-9.3 per 100,000 per year in Europe and North America [21]. In this analysis, it was noted that there was an increase in IPF incidence over time according to most studies, but mortality appears to plateau and even decline in the USA and Denmark [23, 24]. Regarding Greece, 
Karakatsani et al. [19] conducted a multicenter survey in 2009 , using an one-page questionnaire, in order to evaluate the incidence and prevalence of interstitial lung diseases in Greece. Centers covering about $60 \%$ of the Greek population were analyzed. A total of 967 cases of interstitial lung diseases were registered. The most frequent disease was sarcoidosis $(34.1 \%)$, followed in decreasing order by IPF (19.5\%). The annual incidence of IPF was estimated to be 0.93 cases per 100,000 , whereas prevalence was estimated to be 3.38 cases per 100,000 . Since then though, the diagnostic criteria, the international guidelines, the standard medical care, and the composition of the population have changed, and possibly these data do not reflect the current population of IPF patients $[1,15$, 16].

The second limitation is the heterogeneity of the disease. Long-term data on the natural course of IPF are missing. RCTs have proved the efficacy of novel agents after a short period of follow-up (up to 1 year), but epidemiological data show that the median survival of IPF patients may reach up to 5 years [4]. Therefore, the appropriate duration of treatment with novel agents as well as the possible benefit by sequential treatment with these agents cannot be determined by published RCTs. Furthermore, there is a lack of information on detailed patient characteristics. Registries conducted in Germany and Australia $[4,25]$ have provided valuable insights into the baseline characteristics and the natural course of IPF patients diagnosed after the publication of the consensus guidelines in 2011. However, only a small percentage of patients included in these registries were treated with novel agents - all as part of clinical trials or specialized access programs -, therefore further recording of patients is needed in order to assess the effect of novel agents in current clinical practice. Such registries are already ongoing $[4,26-28]$. The last issue regarding the heterogeneity of a disease with relative low incidence and prevalence is the acquisition of data for the treatment of special subpopulations. Post hoc analyses from RCTs for such subpopulations have already been published [11,29-31], but these studies are limited by their post hoc nature and the small number of patients in several subgroups. It should be noted though that the 2015 consensus guidelines urge for further research on the use of nintedanib and pirfenidone, specifically in patients with severe impairment in pulmonary function tests [15].

The final limitation for further development of medicinal treatments in IPF is the cost. Despite the results of RCTs and the published guidelines, the existing financial crisis and the shortage of resources in several public health systems worldwide pose obstacles to the clinical use of both novel agents. Furthermore, these agents have been recently approved, and there are few data available regarding their clinical use in the realworld setting [32-34]. Since cost has been recognized as a major issue in the application of public health policies, more data are needed regarding the clinical use of these agents [15].

\section{Rationale for the Investigating Idiopathic Pulmonary}

Fibrosis in Greece (INDULGE IPF) Registry

All of the above converge to the unmet medical need to collect data on the population of patients diagnosed with IPF, the natural course of the disease, and the medical treatment. In a call for action on an IPF registry by Wilson et al. in 2008 [16], it was noted that improved survival from this disease is dependent on better understanding of its epidemiology, its diagnostic spectrum, and an analysis of outcomes from emerging therapies at a significant level. It is obvious that registries cannot provide level 1 evidence that will guide treatment decisions as to when to start or to stop treatment with novel agents or as to whether these agents could be used sequentially and in which order [35]. However, registries could provide substantial data for the real-world management of IPF patients and even assist in the design of future studies for specific subpopulations. Furthermore, a registry can document the introduction of new treatments and complement data from RCTs. Finally, a registry could assess quality of life issues and the cost-effectiveness of treatment interventions over time. The ongoing experience with national registries in IPF has provided vital insight for the clinical management of the disease and valuable information towards the development of a global registry $[25,36]$.

In this setting, only sparse data regarding IPF epidemiology and its management in Greece are available [19, 32]. No registry for IPF has been conducted in Greece. Therefore, we present an IPF registry - INDULGE IPF that will be conducted in Greece in order to record standard epidemiological parameters. IPF diagnosis will be based on criteria defined according to the consensus statement jointly issued by the ATS/ERS/JRS/ALAT in 2011 for the collection of standard clinical practice data. Moreover, in the current IPF registry, drug utilization and treatment patterns under clinical practice conditions will be documented in detail. Furthermore, health economic aspects will be investigated. 


\section{Study Objectives}

Overall Objectives. The main objective of the INDULGE IPF registry is to gain further knowledge on the characteristics, management, progression, and outcomes of patients with IPF as treated under real-world, clinical practice conditions in Greece. More specifically, this registry is going to: (1) Provide a comprehensive clinical picture for IPF. (2) Track access to health care and cost of caring for IPF patients over time. (3) Examine the implementation of treatment guidelines used on patients diagnosed with IPF according to the existing diagnosis guidelines. (4) Characterize patients on different treatments.

Specific Objectives. The specific objectives of the INDULGE IPF registry are: (1) To describe the characteristics of IPF patients in Greece, including (a) sociodemographic data, (b) IPF risk factors and comorbidities including myocardial infarction, central nervous system infarction, other arterial thromboembolic events, deep vein thrombosis, hemorrhage, gastrointestinal perforation, and pulmonary hypertension, (c) methods used for IPF diagnosis, (d) IPF disease severity as assessed by clinical assessment of symptoms and lung function assessment (pulmonary function test, 6-min walk distance test, and cardiopulmonary exercise testing), and (e) IPF treatment modalities (detailed information regarding pharmacological and non-pharmacological treatment of IPF). (2) To provide information regarding survival and mortality causes among IPF patients in Greece. (3) To prospectively collect outcome data such as IPF exacerbations and hospitalizations. (4) To document treatment patterns (switch/discontinuation of medications). (5) To assess financial aspects (intensity of treatment, resource use, hospitalizations).

\section{Methods}

\section{Design of the INDULGE IPF Registry}

INDULGE IPF allows for structured, prospective, non-interventional collection of data. The study protocol was developed according to the INSIGHTS-IPF registry in Germany [27], which has already produced significant data regarding the management of IPF patients in that country $[25,37,38]$. INDULGE IPF is a national, multicenter, observational disease and outcomes registry based on new data from a significant sample size of Greek IPF patients. Participating physicians will not be subjected to any instructions with regard to the diagnosis and therapy of their patients. However, we aim to have a local review on a national level in order to validate the collected data from all the participating sites. All examinations will be performed according to the discretion and clinical routine of the participating physicians. The patients will be informed about the study and data protection issues with written patient information, and they will provide written informed consent before their enrollment. The study is conducted according to the Greek legislation on non-interventional studies. The study protocol and study documents have been approved by the participating hospitals' scientific committees.

\section{Patients}

Three hundred patients are planned to be enrolled in this registry, fulfilling all of the following criteria: at least 40 years of age and IPF diagnosis based upon the consensus statement jointly issued by ATS/ERS/JRS/ALAT in 2011. Patients will be excluded from the study if they are scheduled for lung transplantation within 6 months or if they are currently participating in clinical trials. Patients will be included in a consecutive manner at each site in order to avoid selection bias. If a patient participates in another registry/non-interventional study, this will be documented and the patient will be analyzed separately.

\section{Study Sites}

Physicians managing IPF patients were eligible for participation in the study considering their qualifications, their past participation and experience in similar clinical studies, and their capacity on recruiting and monitoring patients in the study. In order to ensure adequate patient numbers per center and high quality of data, expert pulmonary centers were involved. Seven university pulmonology clinics and reference centers were selected for this registry (see Appendix). These sites follow up about $70-80 \%$ of IPF patients within the Greek territory.

\section{Study Schedule and Variables}

The study schedule is displayed in Table 1. Briefly, a relevant patient history will be recorded at baseline including the current status of the disease, any IPF-related clinical events and hospitalizations for the past 12 months, and risk of bleeding and thrombosis. At the follow-up visits, performed in the 3rd and 6th month after enrollment and every 6 months thereafter up to 2 years, the above-mentioned parameters will be recorded along with any changes in the pharmacological treatment of patients, any IPFrelated clinical events and hospitalizations among visits, as well as the survival status and the occurrence of outcomes of interest.

\section{Statistical Methods}

The sample size, as well as the duration of the study, was not defined by a formal sample size and power calculation, but were based mainly on the availability of eligible IPF patients as well as the patient populations in the selected sites.

The registry requires collection of new data that are recorded in an existing web-based database in a consecutive manner (electronic case report form) as well as transfer of already existing data to the system from medical charts.

Continuous variables will be listed as median with interquartile range and other percentages, and as mean value with standard deviation, along with minimum and maximum values (depending on the underlying distribution). Categorical values will be listed as absolute and relative frequencies. All events during follow-up will be described as incidence rates with $95 \%$ confidence interval. Stratified analyses will be performed among newly diagnosed patients ( $<6$ months) as well as patients who were diagnosed in the past $(\geq 6$ months). Due to limited number of patients and population heterogeneity, no comparison between treatments can be done and no causal relationship conclusion can be derived (no hypothesis testing). Statistical analyses will be performed with IBM SPSS Statistics (version 19.0). 
Table 1. List of variables to be documented (if available) at scheduled visits

Variable

Eligibility criteria

$\mathrm{x}$

Baseline information (assessment)

(Socio)demographic variables: age, gender, race, height, index, employment status, insurance status

Weight, blood pressure, heart rate

X

$\mathrm{X}$

(Possible) IPF risk factors

Cigarette smoking including pack-years; environmental and occupational exposure; alcohol and substance abuse; exposure $\quad \mathrm{x}$ to drugs associated with IPF; exposure to viral infection possibly related to IPF; gastroesophageal reflux; genetic factors (family history); others

Comorbidities $x$

IPF: baseline information (assessment) on IPF

First symptoms; date of first diagnosis, dates and results of HRCT, surgical lung biopsy, bronchoalveolar lavage

$\mathrm{X}$

Symptoms

Dyspnea, cough, fatigue, dizziness, chest pain, anxiety

Functional assessment

Lung function test (VCin, FVC, FEV1, TLC; DLCO; $\mathrm{pO}_{2}, \mathrm{pCO}_{2}$ ), 6-min walk distance, CPET

$\mathrm{x} \quad \mathrm{X}$

Serologic evaluation: autoimmune biomarkers (laboratory values)

Rheumatoid factor, anti-cyclic citrullinated peptide, and anti-nuclear antibody titer and pattern ${ }^{2}$; others, e.g., SCL-70, SS-A, SS-B; BNP/NT-proBNP Hb, AST, ALT, total bilirubin

Pharmacological treatment (start date, stop date, and daily dose)

Past/discontinued: drugs (e.g., steroids yes/no/unknown)

Current: drugs by class and/or name

Participation in IPF trial

Non-pharmacological treatment

Long-term oxygen therapy (liquid and/or concentrate)

Lung transplantation score and assessment if the patient is currently listed for lung transplantation

Physician assessment

Physician's clinical rating of the probable course of IPF (stable, slow, or rapid progression), based on available

FVC results, DLCO results, physical examination, and hospitalizations/events between the visits

Management of IPF and physician contacts

Number of physician visits (own office, other physicians)

Number and type of IPF-related procedures

Outcomes of interest

\section{Clinical events and hospitalizations}

Specifically due to: (acute) worsening of respiratory function including pneumonia; IPF exacerbations; manifest pulmonary $\mathrm{x}^{3} \quad \mathrm{x}$

or cardiovascular complications; pulmonary rehabilitation; pulmonary embolism; pneumothorax; cardiac failure

Number of days in hospital or in rehabilitation; work days lost due to IPF

Physical examination and vital signs

Risk of bleeding and thrombosis

$\mathrm{X} \quad \mathrm{X}$

$\mathrm{x}$

Survival status (vital status)

$\mathrm{X}$

$x$

ALT, alanine aminotransferase; AST, aspartate aminotransferase; BNP, brain natriuretic peptide; CPET, cardiopulmonary exercise testing; DLCO, diffusing capacity of the lung for carbon monoxide; FEV1, forced expiratory volume in 1 s; FVC, forced vital capacity; Hb, hemoglobin; HRCT, highresolution computed tomography; IPF, idiopathic pulmonary fibrosis; NT-proBNP, N-terminal pro B-type natriuretic peptide; pCO 2 , partial pressure of carbon dioxide; $\mathrm{pO}_{2}$, partial pressure of oxygen; TLC, total lung capacity; VCin, inspiratory vital capacity. ${ }^{1}$ Three months ( \pm 1 month), 6 months ( \pm 1 month), 12 months ( \pm 2 months), 18 months ( \pm 2 months), and 24 months ( \pm 2 months). ${ }^{2}$ As recommended in the ATS/ERS guidelines for distinguishing connective tissue disease from IPF. ${ }^{3}$ The past 12 months.

Design, Rationale, Methodology, and Aims of a Greek Prospective IPF Registry 
Dissemination of Information

The study has been registered at ClinicalTrials.gov under NCT03074149. A study report will be written upon completion of the study. The results will be reported as a peer-reviewed publication.

\section{Discussion}

In this paper, we present the study design and the rationale of the INDULGE IPF registry that has recently started patient enrollment. This study has been designed to collect epidemiological data of IPF patients in Greece as well as their clinical characteristics (such as IPF diagnosis, IPF risk factors, and comorbidities). The treatment pathways chosen by the physicians, the acute exacerbations of the disease, and the utility of health resources will also be determined. INDULGE IPF is characterized by inherent limitations due to its observational, non-randomized design. In order to validate the collected data, we aim to have a local review on a national level. The baseline characteristics of the patients and the clinical decisions of the treating physicians may introduce bias, confounding the associations between treatment and outcome. However, this study will prospectively collect data, providing valuable information regarding IPF management in Greece. It will also complement analogous registries from around the globe $[26,27$, 39,40 ], enforcing scientific attempts towards a global IPF registry that is anticipated to improve the medical treatment and outcome of IPF patients.

\section{Acknowledgments}

Medical writing support was provided by Dr. Michalis Liontos of Phaze CRO, Athens, Greece and funded by Boehringer Ingelheim.

\section{Financial Disclosure and Conflicts of Interest}

Boehringer Ingelheim is the sponsor of the study. D. Bouros reports occasional travel grants, advisory board and/or lecture fees, and department donations from Boehringer Ingelheim, Roche, GSK, Elpen, Pharmathen, Novartis, and Menarini. Z. Daniil reports honoraria and advisory board fees from Boehringer Ingelheim, Roche, Astra, Chiesi, Pharmathen, Novartis, and Elpen, and research support from Boehringer Ingelheim, Roche, and Elpen. D. Papakosta reports advisory panel fees/research grants/honorarium fees from AstraZeneca, Boehringer Ingelheim, Chiesi, Elpen, Pharmathen, Roche, Novartis, and Vianex/ MSD. K.M. Antoniou reports research grants from Boehringer Ingelheim and Roche, advisory board fees from Roche, and travel grants and lectures fees from Roche, Boehringer Ingelheim, Menarini, and Elpen. K. Markopoulou reports travel and research grants from Roche, Boehringer Ingelheim, and Menarini. L. Kolilekas reports speaker fees from Menarini and consultancy fees from Roche. G. Konstantopoulos is an employee of Boehringer Ingelheim. S. Papiris reports speaker and consultancy fees and research grants for his department from Astra Zeneca, Boehringer Ingelheim, Roche, Novartis, Demo, Aspen, Bayer, Elpen, Vianex, and Pharmathen.

\section{Appendix}

\begin{tabular}{|c|c|c|}
\hline Site & Principal investigator & Sub-investigator/study coordinator \\
\hline $\begin{array}{l}\text { 1st Academic Department of Pneumonology, Hospital for Diseases of the Chest } \\
\text { "Sotiria," Medical School, National and Kapodistrian University of Athens, Athens, } \\
\text { Greece }\end{array}$ & Demosthenes Bouros & $\begin{array}{l}\text { - Evangelos Bouros (sub-investigator) } \\
\text { - Argyrios Tzouvelekis (sub-investigator) } \\
\text { - Vasileios Tzilas (sub-investigator) } \\
\text { - Antonou Chrysa (study coordinator) }\end{array}$ \\
\hline $\begin{array}{l}\text { 2nd Respiratory Medicine Department, Medical School, National and Kapodistrian } \\
\text { University of Athens, Attikon General Hospital, Athens, Greece }\end{array}$ & Spyros Papiris & $\begin{array}{l}\text { - Effrosyni Manali (sub-investigator) } \\
\text { - Ioanna Kormpila (sub-investigator) } \\
\text { - Maria Kallieri (sub-investigator) }\end{array}$ \\
\hline $\begin{array}{l}\text { Respiratory Medicine Department, University of Thessaly School of Medicine, } \\
\text { University Hospital of Larissa, Larissa, Greece }\end{array}$ & Zoe Daniil & $\begin{array}{l}\text { - Malli Foteini (sub-investigator) } \\
\text { - Deskata Konstantina (sub-investigator) }\end{array}$ \\
\hline Thoracic Medicine Department, University Hospital of Heraklion, Heraklion, Greece & Katerina M. Antoniou & $\begin{array}{l}\text { - Athina Trachalaki (sub-investigator) } \\
\text { - Evangelia Stamataki (study coordinator) }\end{array}$ \\
\hline $\begin{array}{l}\text { NHS Pulmonology Department, General Hospital of Thessaloniki “G. Papanikolaou," } \\
\text { Thessaloniki, Greece }\end{array}$ & Katerina Markopoulou & $\begin{array}{l}\text { - Diamantis Chloros (sub-investigator) } \\
\text { - Georgia Kounti (sub-investigator) } \\
\text { - Christina Rampiadou (sub-investigator) }\end{array}$ \\
\hline $\begin{array}{l}\text { Pulmonary Medicine Department, General Hospital of Thessaloniki “G. Papanikolaou," } \\
\text { Aristotle University of Thessaloniki Medical School, Thessaloniki, Greece }\end{array}$ & Despoina Papakosta & $\begin{array}{l}\text { - Evangelia Fouka (sub-investigator) } \\
\text { - Ioannis Organtzis (sub-investigator) } \\
\text { - Christoforos Efthimiou (sub-investigator) }\end{array}$ \\
\hline $\begin{array}{l}\text { NHS 7th Pulmonary Department and Asthma Center, Hospital for Diseases of the Chest } \\
\text { "Sotiria," Athens, Greece }\end{array}$ & Likurgos Kolilekas & $\begin{array}{l}\text { - Marianthi Iliopoulou (sub-investigator) } \\
\text { - Konstantinos Loverdos (sub-investigator) }\end{array}$ \\
\hline
\end{tabular}




\section{References}

-1 Raghu G, Collard HR, Egan JJ, Martinez FJ, Behr J, Brown KK, et al: An official ATS/ERS/ JRS/ALAT statement: idiopathic pulmonary fibrosis: evidence-based guidelines for diagnosis and management. Am J Respir Crit Care Med 2011;183:788-824.

-2 Raghu G, Weycker D, Edelsberg J, Bradford WZ, Oster G: Incidence and prevalence of idiopathic pulmonary fibrosis. Am J Respir Crit Care Med 2006;174:810-816.

- 3 Anto JM, Cullinan P: Clusters, classification and epidemiology of interstitial lung diseases: concepts, methods and critical reflections. Eur Respir J Suppl 2001;32:101s-106s.

-4 Jo HE, Glaspole I, Grainge C, Goh N, Hopkins PMA, Moodley Y, et al: Baseline characteristics of idiopathic pulmonary fibrosis: analysis from the Australian Idiopathic Pulmonary Fibrosis Registry. Eur Respir J 2017;49:1601592.

$\checkmark 5$ King TE Jr, Bradford WZ, Castro-Bernardini $>18$ S, Fagan EA, Glaspole I, Glassberg MK, et al: A phase 3 trial of pirfenidone in patients with idiopathic pulmonary fibrosis. N Engl J Med 2014;370:2083-2092.

6 Noble PW, Albera C, Bradford WZ, Costabel U, Glassberg MK, Kardatzke D, et al: Pirfenidone in patients with idiopathic pulmonary fibrosis (CAPACITY): two randomised trials. Lancet 2011;377:1760-1769.

-7 Richeldi L, Costabel U, Selman M, Kim DS, Hansell DM, Nicholson AG, et al: Efficacy of a tyrosine kinase inhibitor in idiopathic pulmonary fibrosis. N Engl J Med 2011;365:10791087.

-8 Richeldi L, du Bois RM, Raghu G, Azuma A, Brown KK, Costabel U, et al: Efficacy and safety of nintedanib in idiopathic pulmonary fibrosis. N Engl J Med 2014;370:2071-2082.

-9 Conte E, Gili E, Fagone E, Fruciano M, Iemmolo M, Vancheri C: Effect of pirfenidone on proliferation, TGF- $\beta$-induced myofibroblast differentiation and fibrogenic activity of primary human lung fibroblasts. Eur J Pharm Sci 2014;58:13-19.

10 Raghu G, Johnson WC, Lockhart D, Mageto Y: Treatment of idiopathic pulmonary fibrosis with a new antifibrotic agent, pirfenidone: results of a prospective, open-label phase II study. Am J Respir Crit Care Med 1999;159: 1061-1069.

-11 Lederer DJ, Bradford WZ, Fagan EA, Glaspole I, Glassberg MK, Glasscock KF, et al: Sensitivity analyses of the change in FVC in a phase 3 trial of pirfenidone for idiopathic pulmonary fibrosis. Chest 2015;148:196-201

12 Chaudhary NI, Roth GJ, Hilberg F, MullerQuernheim J, Prasse A, Zissel G, et al: Inhibition of PDGF, VEGF and FGF signalling attenuates fibrosis. Eur Respir J 2007;29:976985.

13 Coward WR, Saini G, Jenkins G: The pathogenesis of idiopathic pulmonary fibrosis. Ther Adv Respir Dis 2010;4:367-388.

14 Richeldi L, Cottin V, du Bois RM, Selman M, Kimura T, Bailes Z, Schlenker-Herceg R, Stowasser S, Brown KK: Nintedanib in patients with idiopathic pulmonary fibrosis: combined evidence from the TOMORROW and INPULSIS ${ }^{\circledR}$ trials. Respir Med 2016;113:74-79.

15 Raghu G, Rochwerg B, Zhang Y, Garcia CA, Azuma A, Behr J, et al: An official ATS/ERS/ JRS/ALAT clinical practice guideline: treatment of idiopathic pulmonary fibrosis. An update of the 2011 clinical practice guideline. Am J Respir Crit Care Med 2015;192:e3-e19.

16 Wilson JW, du Bois RM, King TE Jr: Challenges in pulmonary fibrosis: 8 - The need for an international registry for idiopathic pulmonary fibrosis. Thorax 2008;63:285-287.

-17 Loveman E, Copley VR, Colquitt JL, Scott DA, Clegg AJ, Jones J, et al: The effectiveness and cost-effectiveness of treatments for idiopathic pulmonary fibrosis: systematic review, network meta-analysis and health economic evaluation. BMC Pharmacol Toxicol 2014;15:63.

8 Musellim B, Okumus G, Uzaslan E, Akgun M, Cetinkaya E, Turan O, et al: Epidemiology and distribution of interstitial lung diseases in Turkey. Clin Respir J 2014;8:55-62.

19 Karakatsani A, Papakosta D, Rapti A, Antoniou KM, Dimadi M, Markopoulou A, et al: Epidemiology of interstitial lung diseases in Greece. Respir Med 2009;103:1122-1129.

20 Coultas DB, Zumwalt RE, Black WC, Sobonya RE: The epidemiology of interstitial lung diseases. Am J Respir Crit Care Med 1994;150: 967-972.

21 Hutchinson J, Fogarty A, Hubbard R, McKeever T: Global incidence and mortality of idiopathic pulmonary fibrosis: a systematic review. Eur Respir J 2015;46:795-806.

22 Gribbin J, Hubbard RB, Le Jeune I, Smith CJ, West J, Tata LJ: Incidence and mortality of idiopathic pulmonary fibrosis and sarcoidosis in the UK. Thorax 2006;61:980-985.

23 Fernandez Perez ER, Daniels CE, Schroeder DR, St Sauver J, Hartman TE, Bartholmai BJ, et al: Incidence, prevalence, and clinical course of idiopathic pulmonary fibrosis: a populationbased study. Chest 2010;137:129-137.

24 Kornum JB, Christensen S, Grijota M, Pedersen L, Wogelius P, Beiderbeck A, et al: The incidence of interstitial lung disease 1995-2005: a Danish nationwide population-based study. BMC Pulm Med 2008;8:24

25 Behr J, Kreuter M, Hoeper MM, Wirtz H, Klotsche J, Koschel D, et al: Management of patients with idiopathic pulmonary fibrosis in clinical practice: the INSIGHTS-IPF registry. Eur Respir J 2015;46:186-196.

26 O’Brien EC, Durheim MT, Gamerman V, Garfinkel S, Anstrom KJ, Palmer SM, et al: Rationale for and design of the Idiopathic Pulmonary Fibrosis-PRospective Outcomes (IPFPRO) registry. BMJ Open Respir Res 2016; 3:e000108.

27 Behr J, Hoeper MM, Kreuter M, Klotsche J, Wirtz $\mathrm{H}$, Pittrow D: Investigating significant health trends in idiopathic pulmonary fibrosis (INSIGHTS-IPF): rationale, aims and design of a nationwide prospective registry. BMJ Open Respir Res 2014;1:e00010.
28 Doubková M, Švancara J, Svoboda M, Šterclová $\mathrm{M}$, Bartoš V, Plačková M, et al: EMPIRE Registry, Czech Part: Impact of demographics, pulmonary function and HRCT on survival and clinical course in idiopathic pulmonary fibrosis. Clin Respir J 2017, Epub ahead of print.

29 Raghu G, Wells AU, Nicholson AG, Richeldi L, Flaherty KR, Le Maulf F, et al: Effect of nintedanib in subgroups of idiopathic pulmonary fibrosis by diagnostic criteria. Am J Respir Crit Care Med 2017;195:78-85.

30 Kolb M, Richeldi L, Behr J, Maher TM, Tang W, Stowasser S, et al: Nintedanib in patients with idiopathic pulmonary fibrosis and preserved lung volume. Thorax 2017;72:340-346.

31 Nathan SD, Albera C, Bradford WZ, Costabel U, du Bois RM, Fagan EA, et al: Effect of continued treatment with pirfenidone following clinically meaningful declines in forced vital capacity: analysis of data from three phase 3 trials in patients with idiopathic pulmonary fibrosis. Thorax 2016;71:429-435.

- 32 Tzouvelekis A, Ntolios P, Karampitsakos T, Tzilas V, Anevlavis S, Bouros E, et al: Safety and efficacy of pirfenidone in severe idiopathic pulmonary fibrosis: a real-world observational study. Pulm Pharmacol Ther 2017;46:48-53.

33 Hughes G, Toellner H, Morris H, Leonard C, Chaudhuri N: Real world experiences: pirfenidone and nintedanib are effective and well tolerated treatments for idiopathic pulmonary fibrosis. J Clin Med 2016;5:E78.

34 Cottin V, Maher T: Long-term clinical and real-world experience with pirfenidone in the treatment of idiopathic pulmonary fibrosis. Eur Respir Rev 2015;24:58-64.

35 Borie R, Justet A, Beltramo G, Manali ED, Pradère $\mathrm{P}$, Spagnolo $\mathrm{P}$, et al: Pharmacological management of IPF. Respirology 2016;21:615625.

36 Moodley Y, Goh N, Glaspole I, Macansh S, Walters EH, Chapman S, et al: Australian Idiopathic Pulmonary Fibrosis Registry: vital lessons from a national prospective collaborative project. Respirology 2014;19:1088-1091.

37 Kreuter M, Swigris J, Pittrow D, Geier S, Klotsche J, Prasse A, et al: Health related quality of life in patients with idiopathic pulmonary fibrosis in clinical practice: INSIGHTS-IPF registry. Respir Res 2017;18:139.

- 38 Pittrow D, Klotsche J, Kreuter M, Hoeper MM, Wirtz H, Koschel D, et al: Symptom burden and health related quality of life in patients with idiopathic pulmonary fibrosis in clinical practice: INSIGHTS-IPF Registry. Value Health 2014;17:A600.

39 Glaspole IN, Chapman SA, Cooper WA, Ellis SJ, Goh NS, Hopkins PM, et al: Health-related quality of life in idiopathic pulmonary fibrosis: data from the Australian IPF Registry. Respirology 2017;22:950-956.

40 Ferrara G, Carlson L, Palm A, Einarsson J, Olivesten C, Skold M: Idiopathic pulmonary fibrosis in Sweden: report from the first year of activity of the Swedish IPF-Registry. Eur Clin Respir J 2016;3:31090.
Design, Rationale, Methodology, and Aims of a Greek Prospective IPF Registry 